\title{
Stable partial dehiscence of aortic homograft inserted freehand by using the subcoronary intra-aortic root noncoronary sinus Ross scallop inclusion technique
}

\author{
Richard Hopkins, MD, ${ }^{a}$ Howard Gitter, MD, ${ }^{\mathrm{b}}$ Jeffrey Stave, DO, ${ }^{\mathrm{c}}$ Arthur Bert, MD, ${ }^{\mathrm{d}}$ and Michael Atalay, MD,
} Kansas City, Mo, Philadelphia, Pa, Des Moines, lowa, and Providence, RI

丹 Supplemental material is available online.

$\mathrm{T}$ echnical error with homograft aortic valve replacements, particularly with the subcoronary technique, although rare $(<2 \%)$, is the most common cause of early to midterm failures. ${ }^{1}$ In general, these technical difficulties result in progressive aortic insufficiency and failure of the homograft. In this case, the patient has had a partial dehiscence for 15 years of the upper portion of the noncoronary cusp flange, which was inserted in the subcoronary position within the aortic root by using the modified scallop cylindersubcoronary inclusion technique (minimal scallop of noncoronary sinus per the 1987 Ross method). ${ }^{2,3}$

\section{Clinical Summary}

A 60 -year-old patient presented 15 years after aortic valve replacement with a cryopreserved human aortic valve homograft. The patient was doing extremely well and was very active, including running and working out with weights. Echocardiographic analysis, cardiac magnetic resonance imaging, and computerized cardiac tomographic analysis all demonstrated excellent aortic valve geometry and ventricular function but also a "fluttering" of the top of the noncoronary cusp of the homograft aortic valve within the aortic root that was timed to

\footnotetext{
From the Division of Cardiothoracic Surgery and the Cardiac Surgical Research Institute, ${ }^{a}$ Children's Mercy Hospital, Kansas City, Mo; Drexel University College of Medicine, ${ }^{\mathrm{b}}$ Philadelphia, Pa; the College of Osteopathic Medicine and Surgery, ${ }^{\mathrm{c}}$ Des Moines University, Des Moines, Iowa; the Department of Anesthesiology, ${ }^{\mathrm{d}}$ Rhode Island Hospital and Brown Medical School, Providence, RI; and the Department of Diagnostic Imaging, ${ }^{e}$ Brown Medical School, Providence, RI.

Richard Hopkins reports a consulting relationship with LifeNet.

Received for publication March 6, 2007; revisions received April 3, 2007; accepted for publication April 11, 2007.

Address for reprints: Richard Hopkins, MD, Adult/Adolescent Congenital Cardiac Surgery, Cardiac Surgical Research Institute, Children's Mercy Hospital, 4 West Tower-Cardiac Surgery, 2401 Gillham Rd, Kansas City, MO 64108 (E-mail: rahopkins@ @ cmh.edu).

J Thorac Cardiovasc Surg 2008;135:214-6

$0022-5223 / \$ 34.00$

Copyright $\odot 2008$ by The American Association for Thoracic Surgery doi:10.1016/j.jtcvs.2007.04.076
}

the cardiac cycle (Figure 1). Review of serial postoperative echocardiograms over the past 15 years indicated that this abnormality was present since early after surgical intervention. Leaflet motion was well maintained, with only 2 small jets of aortic insufficiency (created at the noncoronary-left coronary artery commissure) rated as trace to mild. There was no calcification of the valve leaflets or aortic root.

\section{Discussion}

Sir Donald Ross ${ }^{3}$ suggested that by retaining the donor noncoronary sinus, this method improved alignment of the commisural pillars and "reinforced" the aortotomy suture line (Figure 2 ). The partially retained sinus flange evolved as a modification of his original triple sinus resection for subcoronary insertions. In this case the leaflets have remained pliable for 15 years and have good central coaptation with some asymmetry of coaptation between the left and noncoronary cusps. The commisural pillars are well maintained, oriented appropriately, and in an excellent position.

The dehiscence appears to be along the top of the distal running suture line across the noncoronary scallop near the sinotubular junction reconstruction (Figure 2). Later in diastole, the noncoronary sinus movement (floppy flange) is outward toward the native aortic wall, thus tensing the cusp and assisting in the transfer of diastolic tension from the cusp to the aortic wall. Late in systole, DaVinci currents begin behind the cusp, thus assisting closure and also redistributing leaflet stresses and wall tension (Figure E1). This dynamic motion of the homograft aortic root complex, although different than elastic hydraulic models of the normal aortic root, seemingly could accomplish similar goals of minimizing focal stress/strain deformations by distributing the tension more uniformly across the cusp as a sinus adaptive mechanism. ${ }^{4}$ Fifteen years of excellent homograft function without evidence of any calcification is very encouraging evidence of superior allograft durability for this patient. The durability evidenced by this particular cryopreserved homograft valve might also be due to reduced antigen load by specific processing and thawing methods, by serendipitous HLA similarities to the recipient, or both. The tissue was matched for ABO blood type. The homograft was processed and cryopreserved with the protocols of LifeNet Tissue Services (Norfolk, Va), which include steps intentionally designed to remove endothelium, to remove superficial matrix cells, and to gradually reduce the viability of interstitial cells (myofibroblasts) after implantation through noninflammatory apoptosis rather than proinflammatory cell necrosis. ${ }^{5, \mathrm{E} 1-\mathrm{E} 4}$ 

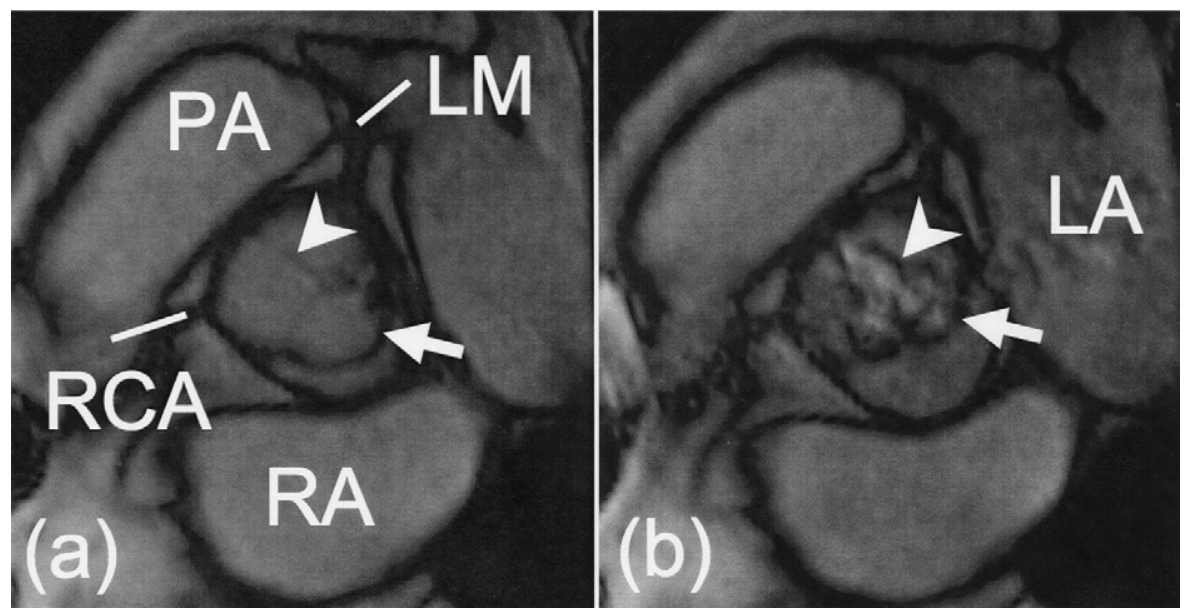

Figure 1. (a) Transverse axis magnetic resonance image through the aortic root demonstrates the dehiscence flap (short arrows) adjacent to the aortic valve (arrowheads). (b) The image is during midsystole. The blind-ending pouch created by the dehiscence increases in size during systole, slightly compressing the noncoronary sinus. $P A$, Pulmonary artery; $L A$, left atrium; $L M$, left main coronary artery; $R C A$, right coronary artery; RA, right atrium.

Most technical malfunctions of allograft valve reconstructions require removal and replacement of the valve. This case is an unusual complication that might be unique to the implantation method but, theoretically, could occur with any of the inclusion techniques that retain sinuses (eg, miniroot, inclusion roots, and intra-aortic cylinders). Some methods of insertion of stentless xenograft valves could also be liable to this complication. We rarely use inclusion methods anymore, having replaced virtually all intra-aortic techniques with valve leaflet salvage or autograft root (the Ross procedure), allograft (homograft) root, or xenograft stentless root replacements. ${ }^{\text {E5-E7 }}$

This "fluttering sinus" has not resulted in further disruption of suture lines, significant hemodynamic malfunction, perivalvular leak, thrombus formation, or emboli. The patient is not receiving warfarin and maintains a physically active, healthy, and vigorous lifestyle. This finding does not necessarily require reoperation (Figure E1).

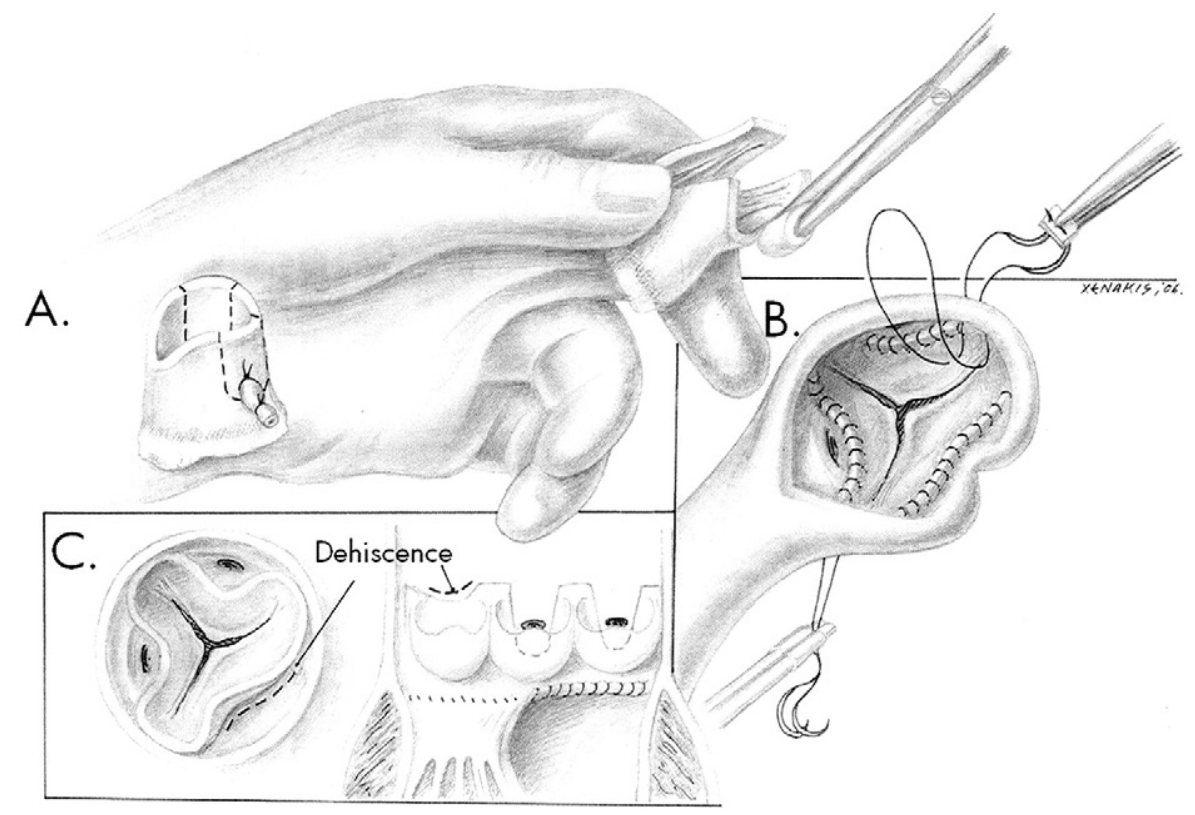

Figure 2. The subcoronary inclusion "scallop" technique in which more of the homograft noncoronary sinus is retained, putatively for better pillar alignment and "reinforcement" of the aortotomy. A, The aortic allograft is trimmed with extensive removal of sinus tissue, except for the noncoronary sinus, in which a shallow scallop is created to fit below the native (recipient) aortotomy. B, After the circumferential proximal suture line is completed, the distal suture line is constructed with 3 polypropylene sutures, beginning at the bottom of each sinus and finishing at the top of each commisural pillar. The knot is placed outside the aorta to reduce thromboembolic risk. C, It is at the top of the "scalloped" sinus where the suture line has pulled through, allowing fluttering and thereby creating the blind pouch. Native aorta outside the allograft is not deformed. 


\section{References}

1. Kilian E, Oberhoffer M, Gulbins H, Uhlig A, Kreuzer E, Reichart B. Ten years experience in aortic valve replacement with homografts in 389 cases. J Heart Valve Dis. 2004;13:554-9.

2. Hopkins RA. Freehand aortic valve replacement with aortic allograft valve transplant aortotomy. In: Hopkins RA, ed. Cardiac reconstructions with allograft tissues. New York: Springer-Verlag; 2005. p. 275-99.
3. Ross DN. Application of homografts and clinical surgery. J Card Surg. 1987;2:175-83.

4. Schoen FJ. Are immune mechanisms important in tissue heart valve failure? A debate. J Heart Valve Dis. 2001;10:458-9.

5. Wolfinbarger L, Brockbank K, Hopkins RA. Application of cryopreservation to heart valves. In: Hopkins RA, ed. Cardiac reconstructions with allograft tissues. New York: Springer-Verlag; 2005. p. 133-60. 


\section{E-References}

E1. Hilbert SL, Schoen FJ, Ferrans VJ. Allograft heart valves: morphologic, biochemical, and explant pathology studies. In: Hopkins RA, ed. Cardiac reconstructions with allograft tissues. New York: Springer-Verlag; 2005. p. 193-233.

E2. Mitchell RN, Jonas RA, Schoen FJ. Pathology of explanted cryopreserved allograft heart valves: comparison with aortic valves from orthotopic heart transplants. J Thorac Cardiovasc Surg. 1998;115: 118-27.

E3. Messier R Jr, Domkowski P, Aly H, Hilbert S, Crescenzo D, AbdElfattah A, et al. Adenine nucleotide depletion in cryopreserved human cardiac valves: the "stunned" leaflet interstitial cell population. Cryobiology. 1995;32:199-208.
E4. Messier R, Bass B, Jones J, Domkowski P, Hopkins R. Interstitial cellular and matrix restoration of cardiac valves following cryopreservation. J Thorac Cardiovasc Surg. 1999;118:36-49.

E5. Hopkins RA. Aortic root replacement with aortic allograft conduit. In: Hopkins RA, ed. Cardiac reconstructions with allograft tissues. New York: Springer-Verlag; 2005. p. 318-26.

E6. Hopkins RA. Aortic valve leaflet sparing and salvage surgery: evolution of techniques for aortic root reconstructions. Eur J Cardiothorac Surg. 2003;24:886-97.

E7. Brown JW, Ruzmetov M, Fukui T, Rodefeld MD, Mahomed Y, Turrentine MW. Fate of the autograft and homograft following Ross aortic valve replacement: reoperative frequency, outcome, and management. J Heart Valve Dis. 2006;15:253-60.
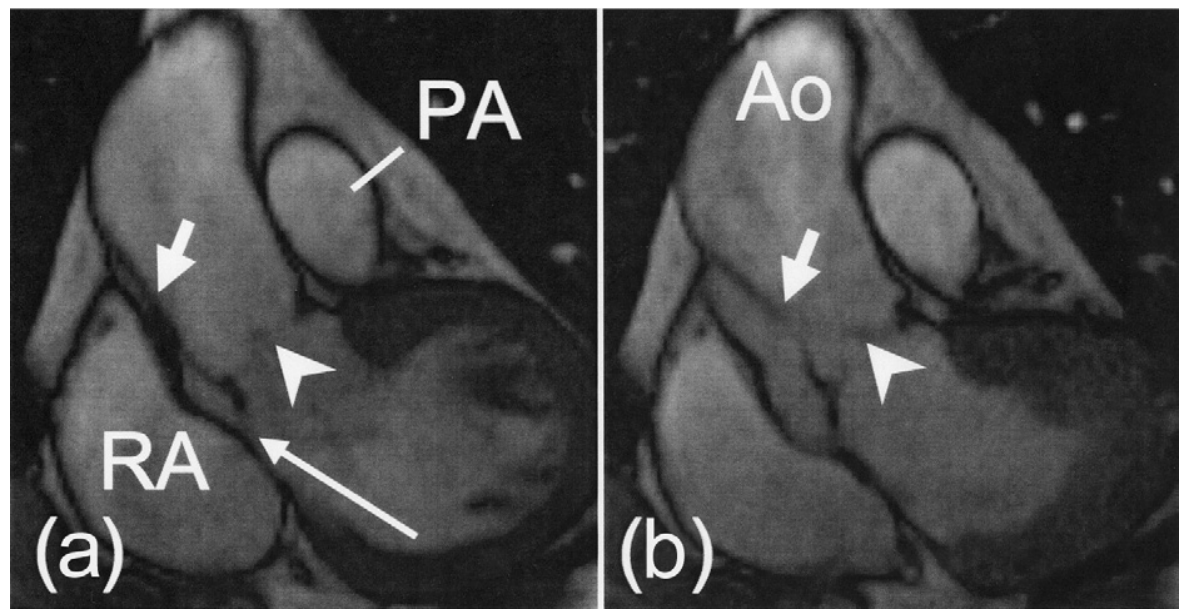

Figure E1. Long-axis companion images to Figure 1. (a) The long arrow indicates the entry site into the pouch. (b) Note increase in pouch size during systole. PA, Pulmonary artery; RA, right atrium; Ao, aorta. 